\title{
Discussion on Effect of High Strength Concrete on Prestressed Concrete Girder Bridge
}

\author{
Guojie Ren \\ The First Branch, CCCC First Highway Consultants CO.LTD, \\ Xi'an 710075, China \\ kqi123456789@163.com
}

\begin{abstract}
High strength concrete materials have been widely used in bridge engineering. Combined with a high strength concrete girder bridge in Texas of U.S, this paper analyzes the impacts of high strength concrete materials in bridge design. Based on analyzing the economic benefit, it clearly shows the high strength concrete materials can significantly reduce the project cost; Finally, the paper puts forward the mix proportion and strength test results in the production of high strength concrete.
\end{abstract}

Keywords-bridge engineering; high strength concrete; economy; mixture ratio design; strength test

\section{INTRODUCTION}

In the last 20 years, it had made amazing progress in the field of high strength concrete production technology[1]. Now, the strength of high strength concrete using the optimal proportion and mixing with high efficiency water reducing agent can reach more than $83 \mathrm{MPa}$. Strength can also reach higher when it use some hard material such as fly ash, ground slag and silicon powder, etc. Recently in some tall buildings, concrete strength has amounted to $113 \mathrm{Mpa}$. The high strength concrete can be obtained through the following ways: using silicon powder, high quality of the aggregate particles, low water cement ratio and high efficiency water reducing agent[2].

Although we can produce, it remains very cautious about using high strength concrete on Engineer industry. So, this attitude is understandable, because the current concrete specification and design formulas are empirical[3]. At the meantime, the terms have been formulated according to "normal strength concrete". However, there are a lot of research on theory and some successful engineering practice. So use the behavior of high strength concrete is a wise move, it will bring significant economic benefits[4].

\section{DESIGN SCHEME SELECTION OF BRAKE LANE BRIDGE}

With real bridge in Texas of U.S named Brake Lane Bridge as an example, this paper does some work about the choice of high strength concrete material design. It is a bridge crossing with straight beam, $\mathrm{C}$ section. The length of bridge is 26 meters, using a total of 22 beams.

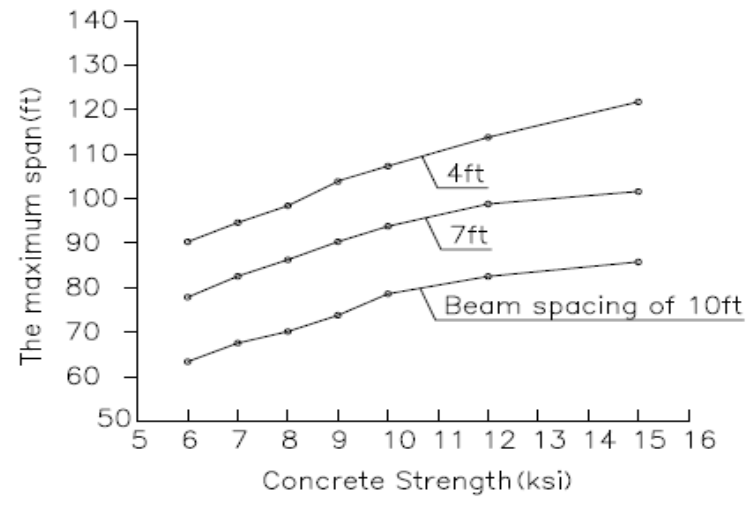

Figure 1. The relation of maximum span and concrete strength Note: $1 \mathrm{ft}=0.3048 \mathrm{~m}, 1 \mathrm{ksi}=6.895 \mathrm{MPa}$

C type beam height of $1016 \mathrm{~mm}$, it is a kind of common section. But, this bridge has a major breakthrough in terms of beam length and the distance. When the strength of concrete girders is $41 \mathrm{Mpa}$, the biggest span of bridge is $24 \mathrm{~m}$ with $2.1 \mathrm{~m}$ beam spacing. And it is $19.2 \mathrm{~m}$ with $3.0 \mathrm{~m}$ beam spacing. When the beam spacing is $2.6 \mathrm{~m}$, the biggest span of bridge is $22 \mathrm{~m}$ with $41 \mathrm{Mpa}$ concrete, and it has reached the $26 \mathrm{~m}$ when $66 \mathrm{Mpa}$ concrete is used. Compared with low strength concrete, bridge span length increased about $22 \%$ that consistent with figure 1 . The other hand, it will be altogether 36 beams with $26 \mathrm{~m}$ span if $41 \mathrm{MPa}$ concrete is used. However, the actual bridge use only 22 beams.

\section{THE INFLUENCE OF HIGH STRENGTH CONCRETE ON BRIDGE DESIGN}

The university of Texas selected 12 different girder cross section to verify the effect of different strength concrete on the biggest span and spacing. The results discussed below[5]:

1. When the cross section of a certain, with the increase of concrete strength, span can be increased $10 \%$ to $40 \%$.

2. When the span of a certain, with the increase of concrete strength, beam spacing can be widened to reduce the number of beam. In some cases, the girder spacing can be doubled.

3. Using high strength concrete, the requirements of the concrete strength when release prestress can be reduced.

4. The transfer length of prestressed reinforcement in 
high strength concrete is shorter in length than the normal concrete.

5. In the narrow section, high strength concrete can be smooth gating only with the help of high plastic minimised water-based agent.

When the girder spacing is $1.2 \mathrm{~m}$ and $2.1 \mathrm{~m}$, concrete strength by $41 \mathrm{MPa}$ to $103 \mathrm{MPa}$, figure 2 shows the increase in beam span. Can be seen in the figure, the span of beam can be increased by more than $20 \%$ when strength increased from $41 \mathrm{MPa}$ to $69 \mathrm{MPa}$.

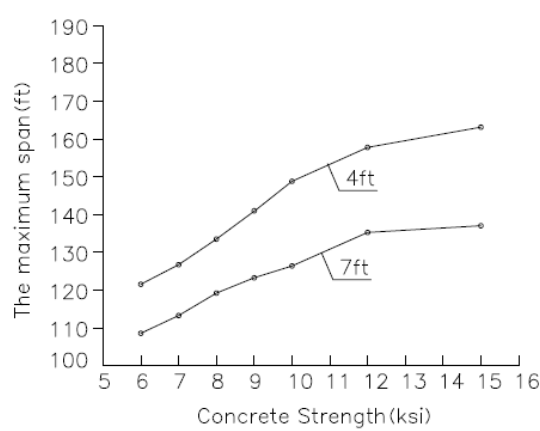

Figure 2. the relationship of maximum span and concrete strength

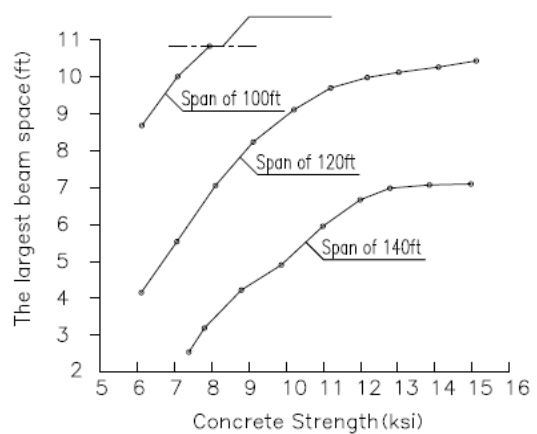

Figure 3. the relationship of the largest beam space and concrete strength

Figure 3 shows the change of three different span girder spacing along with the increase of concrete strength. Girder spacing can be widened by $1.2 \mathrm{~m}$ to $2.7 \mathrm{~m}$ when the span is $37 \mathrm{~m}$ and strength increased from $41 \mathrm{MPa}$ to $69 \mathrm{MPa}$. It's about more than double increased.

As can be seen from the figure 2 and figure 3, the rise curve slope of high strength concrete benefits began to slow when the concrete strength is more than $69 \mathrm{MPa}$. This means that the advantage of high strength concrete has been weakened. This is due to that it needs to add more prestressed reinforcement in order to obtain high strength concrete. Thus, it makes the prestressed eccentricity becomes smaller.

When the dosage of the steel strand exceeds a certain limit, due to the clear distance, it have to decorate the steel strand in the high places and even into the web of the beam. And in these places, steel strand does little to improve the flexural capacity. As can be seen from the figure 4, once the number of steel strand exceeds a certain number, the product of the number of steel strand with eccentricity will not be increase, and even decrease in some cases.

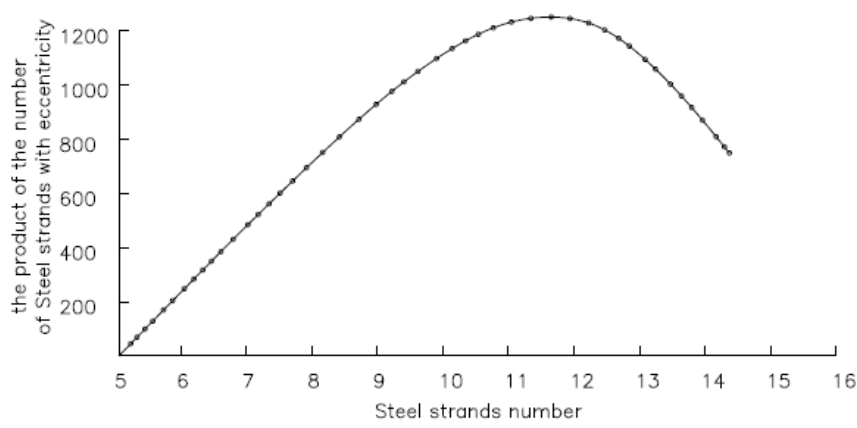

Figure 4. The relationship of Steel strands number and the product of the Steel strands with eccentricity

Figure 5 shows the beam which spacing is $2.1 \mathrm{~m}$. When the concrete strength exceed $69 \mathrm{MPa}$, we need more than 60 steel strand $(\varphi 12.5$ diameter 7 wire 1860 level low relaxation strand ). This is the limit that ascensional range began to slow of the product of the number of steel strand with eccentricity. Therefore, if you want to effectively use the high strength concrete of strength for more than $69 \mathrm{MPa}$, we must use the high tensile steel strand. As can be seen from the figure 6 , it can make the beam bending capacity continues to grow when use $\varphi 15 \mathrm{~cm}$ diameter steel strand.

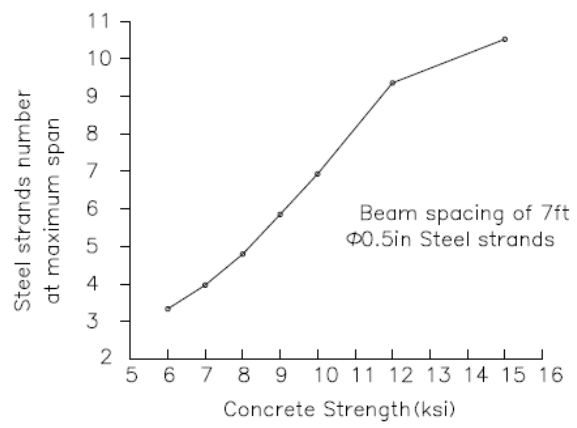

Figure 5. The relationship of steel strands number and concrete strength

In order to confirm the growth effect of beam's bending capacity, two similar bridges with different concrete strength were compared. They have the same parameters and materials including 11 meters wide and 35 meters span. And they use the same cross section of girder, $\varphi 13 \mathrm{~cm}$ low relaxation strand and the bridge deck pavement using $28 \mathrm{MPa}$ concrete strength. The final design results are shown in figure 7 . It need four beams and 232 strands when using $69 \mathrm{MPa}$ concrete. And it need nine beams and 270 strands when using $41 \mathrm{MPa}$ concrete. The former bridge panel was slightly upset just because beam spacing is bigger. 


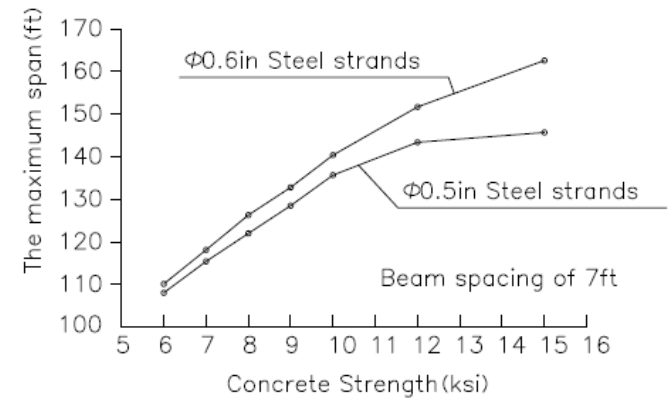

Figure 6 . The relationship of the maximum span and concrete strengtn

\section{ECONOMIC BENEFITS}

The main reason to use the high strength concrete is trying to reduce the total cost. At the same time, it can save expensive bridge investment to the construction company. And it also make the bridge factory be more competitive .

The cause of the high strength concrete can reduce cost can be analyzed from the following several aspects:

First of all, although the unit price of concrete increases, it will recover from the amount of savings. Brakec bridge is one example which only use 11 beams each span. However, it will be 17 beams if we use relatively low $41 \mathrm{MPa}$ strength concrete.

Second, the cost of prestressed reinforcement remain unchanged. With the increase of concrete strength, the total number of prestressed reinforcement is only slightly reduced. Although the beam number has decreased, but the quantities of each beam's prestressed reinforcement is increased. And the final amount is usually not big changes.

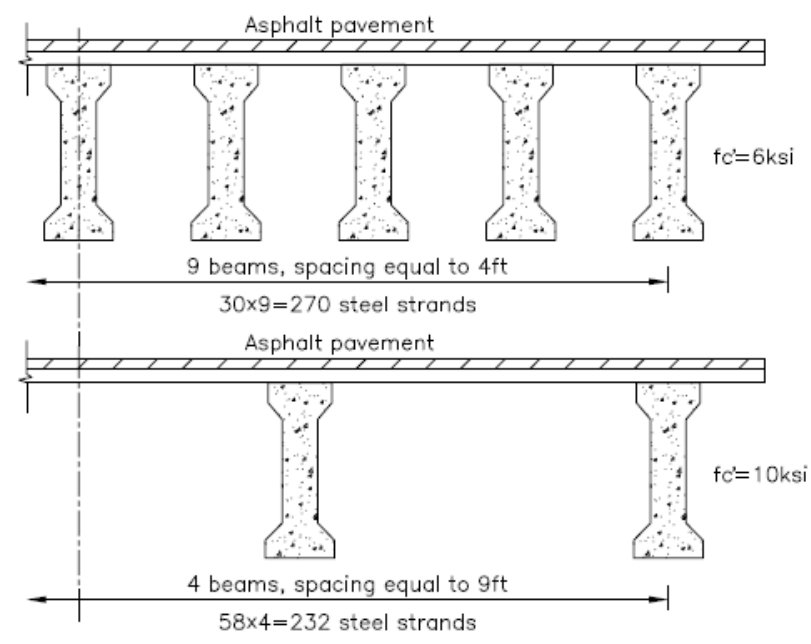

Figure 7. comparison of the bridge design

The most significant savings using high strength concrete are that it can reduce the "not material cost" of beam. The so-called "not material cost" refers to the labor cost, and installation costs for beam transport and other indirect costs. In terms of every piece of the beam itself, both with high strength and ordinary concrete, "the not material cost" is the same. The reason of saving is that it reduced the number of the beam.

Cost comparison on the example in figure 7 is shown in table I. Showing two different mix proportio in the table, it can be seen that $30 \%$ total cost was saved although the unit price of high strength concrete is more than double that of ordinary concrete. On the other hand, the attraction of high strength concrete is that it can increase the durability. Especially in the corrosive environment such as coastal areas or somewhere often sprinkling melt ice salt, it has more advantages. Using silica powder not only can obtain high strength, and also it can increase the durability because of its low permeability greatly.

TABLE I. COMPARISON OF THE DESIGN COST OF FIGURE 7(UNITS:\$M)

\begin{tabular}{lllr}
\hline Engineering parts & $\begin{array}{l}\text { coal ash adopting } \\
\text { 41Mpa Concrete }\end{array}$ & $\begin{array}{l}\text { Ganister } \\
\text { adopting } \\
\text { Concrete }\end{array}$ & $\begin{array}{r}\text { sand } \\
69 \mathrm{Mpa}\end{array}$ \\
Deck & 697 & 881 & \\
Steel strand & 354 & 304 & \\
Beam concrete & 240 & 226 & \\
not material cost & 1378 & 613 & \\
total & 2669 & 2025 & \\
\hline
\end{tabular}

\section{DESIGN OF MIX PROPORTION}

There are many factors that can affect the strength of concrete such as: material proportion, high efficiency water reducing agent dosage, aggregate sources, curing conditions, pitch mix etc. When the concrete mixed with silicon powder in the process of production, actual mix proportion and strength test results are shown in table II and table III.

TABLE II. THE ACTUAL MIX PROPORTION

\begin{tabular}{|c|c|c|}
\hline Mate & \multicolumn{2}{|c|}{ Dosage $\left(\mathrm{kg} / \mathrm{m}^{3}\right)$} \\
\hline Cem & \multicolumn{2}{|c|}{323} \\
\hline Coal & \multicolumn{2}{|r|}{124} \\
\hline Cani & \multicolumn{2}{|r|}{47} \\
\hline Coarse a & \multicolumn{2}{|r|}{1063} \\
\hline Fine ag & \multicolumn{2}{|r|}{623} \\
\hline Wa & \multicolumn{2}{|r|}{139} \\
\hline Water-cen & \multicolumn{2}{|r|}{0.3} \\
\hline Reta & \multicolumn{2}{|r|}{0.44} \\
\hline HR Water re & \multicolumn{2}{|r|}{1.9} \\
\hline \multicolumn{3}{|c|}{ TABLE III. CONCRETE COMPRESSIVE STRENGTH(THE AVERAGE) } \\
\hline NO. & Time & Compressive strength \\
\hline \multirow{3}{*}{ The First } & $7 \mathrm{~d}$ & 77 \\
\hline & $14 \mathrm{~d}$ & 93 \\
\hline & $28 \mathrm{~d}$ & 92 \\
\hline \multirow{4}{*}{ The Scecond } & $82 \mathrm{~h}$ & 70 \\
\hline & $7 d$ & 80 \\
\hline & $14 d$ & 86 \\
\hline & $28 \mathrm{~d}$ & 98 \\
\hline \multirow{3}{*}{ The Third } & $12.5 \mathrm{~h}$ & 52 \\
\hline & $8 \mathrm{~d}$ & 86 \\
\hline & $26 \mathrm{~d}$ & 88 \\
\hline
\end{tabular}

The value of silicon powder concrete slump is $102-191 \mathrm{~mm}$, and it has the very good work performance. Complete casting girder must be finished within 30 minutes and in the process of casting must also be required to take concrete measures to prevent the lost of surface water. 


\section{CONCLUSION}

Through the actual design and economic comparison, it shows that the high strength concrete bridges have great advantage. It can obviously reduce the bridge cost, and improve the durability of the bridge. Through the successful application in the engineering practice, the high strength concrete will become an acceptable material in engineering. It will bring great benefits to engineers, developers, precast concrete manufacturers as well as the social public.

\section{REFERENCES}

[1] Wang Zhen-Yu. Seismic performance of reinforced concrete frame columns in Hong Kong[J]. Journal of Harbin institute of architecture, 2001, 34(2): 6-11

[2] Zhang Guo-Jun. Preparation on and application of high strength concrete [J]. Low Temperature Architecture Technology, 2001,2:11-13

[3] Yang Xiao-Ming. Experimental study on aseismic performance of RC column under different loading systems. Industrail Constructon. 2005, 35(9): 42-45

[4] Attard MM, Setunge S. The stress-strain relationship of confined and unconfined concrete[J]. ACI Materials Journal, 1996, 93(5): 432-442

[5] KangQi,Aseismic Performance Analysis of High-Strength Concrete Circular Pier[C]. Applied Mechanics and Materials Vol. 431(2013) pp 161-166 